\title{
Abnormalities in sensory and mixed evoked potentials in ataxia-telangiectasia
}

\author{
A-Cruz Martínez, M. BARrio, A. M. Gutierrez, AND E. López
}

From S. Carlos University Hospital, Faculty of Medicine, Madrid, Spain

SUMMARY Electromyography, motor, sensory and mixed nerve conduction velocity, and $H$ reflex were studied in four patients with ataxia-telangiectasia. The earliest and most striking electrophysiological finding was the reduced amplitude of evoked nerve potentials. In the oldest patient, findings suggestive of spinal atrophy and mild reduction of the motor and sensory nerve conduction velocities were found. Reduced amplitude in the evoked nerve potentials can be observed without clinical evidence of peripheral neuropathy. Electrophysiological abnormalities are more severe in older than in young patients. Sural nerve biopsy in one patient showed mild changes: loss of the largest myelinated fibres and demyelination of some fibres. The ratio between maximum conduction velocity of the sural nerve and the diameter of the largest fibres was in the lower limits of the normal range. The resemblance between electrophysiological abnormalities in Friedreich's ataxia and ataxia-telangiectasia is discussed.

Ataxia-telangiectasia is a heredofamilial syndrome, transmitted by an autosomal recessive gene (Tadjoedin and Fraser, 1965), and described first by Syllaba and Henner (1926) and Louis-Bar (1941). Later this syndrome was separated from other ataxias and considered as a new entity (Boder and Sedgwick, 1957, 1958).

The disease begins in infancy, and the main clinical features are progressive cerebellar ataxia, oculocutaneous telangiectasia, and frequent sinopulmonary infections. Other symptoms which may be observed are choreoathetosis, dysarthria, apraxia of eye movements, characteristic facies, and growth retardation. An immunological defect is constant: dysgammaglobulinaemia with decreased or absent serum IgA (Fireman et al., 1964), atrophic thymus, and impairment of delayed hypersensitivity responses (Peterson et al., 1963).

Necropsy reveals cerebellar degeneration (Boder and Sedgwick, 1957), loss of myelinated nerve fibres in the posterior columns of the spinal cord (Boder and Sedgwick, 1958; Strich, 1966), degenerative changes in the anterior horns, more striking in advanced cases (Aguilar et al., 1968; Goodman et al., 1969), and reduced size of the nerve cells with reduced number of the satellite cells in the dorsal root ganglia (Strich, 1966).

Accepted 9 September 1976
Muscle biopsy has shown signs of denervation atrophy in advanced cases (Engel et al., 1966; Goodman et al., 1969), especially in distal muscles (Strich, 1966). Only moderate changes in Schwann cells have been described in sural nerve biopsies and necropsies (Strich, 1966; Goodman et al., 1969; Gardner and Goodman, 1969).

Electrophysiological studies have not been published extensively. The EMG is described as neurogenic (Goodman et al., 1969), and nerve conduction velocity is reported in the low limits of normality (Dunn et al., 1964) or in normal limits (Karpati et al., 1965).

This paper presents an electrophysiological study in four patients with ataxia-telangiectasia, with special regard to pathological features of nerve action potentials which have been rarely described before.

\section{Methods}

Four patients (three males and one female) with ataxia-telangiectasia were studied. Their ages were $8,7,12$, and 18 years. Cases 3 and 4 were siblings. Case 2 had been studied previously two years before.

The muscles were examined with coaxial needle electrodes. The motor conduction velocity (MCV) was determined in upper and lower limbs. Evoked potentials of muscle were recorded with coaxial 44 
needle, and the nerves were stimulated percutaneously with supramaximal stimuli at two points.

Sensory nerve conduction velocity (SCV) was determined in the median nerve (digits 1 and 2 to wrist) and sural nerve (lateral malleolus of fibula to lower third of posterior part of leg, slightly lateral to midline). The evoked sensory nerve potential (SEP) was recorded with surface electrodes and bipolar technique $(20 \mathrm{~mm}$ separation between electrodes). Mixed nerve conduction velocity (MxCV) was determined for the wrist-elbow segment, stimulating the median nerve at the wrist. An average of 100 ordinates was used to study the SEP and mixed evoked potential (MxEP). The $\mathrm{H}$ reflex was explored in cases 1 and 3. The MCV, SCV, and MxCV and the peak to peak amplitude of the nerve potentials were compared with normal values of healthy subjects of the same age.

In case 1 muscular and nerve biopsies were performed.

\section{Results}

Ataxia-telangiectasia was diagnosed with the abovementioned criteria. The main features are shown in Table 1.

The EMG was normal in cases 1 and 2, not performed in case 3 , and abnormal in case 4 . Fibrillation, positive sharp waves, and fasciculation were detected in the tibialis anterior muscle, and a neurogenic pattern (high-voltage, long duration, and discrete motor unit activity during full effort) in tibialis anterior and rectus femoris muscles. Case 4 was the most severely affected patient (Table 1), and she is confined to a wheel chair (Fig. 1). This patient presented muscular atrophy and muscular weakness in the lower limbs, equinovarus (Fig. 1), loss of deep sensation in the legs, and kyphoscoliosis.

The MCV was in the lower limits of the normal range in the knee-ankle segment of the peroneal nerve in case 1, and in the elbow-wrist segment of the median nerve in case 4 . Terminal motor latency was mildly prolonged in the peroneal and posterior tibial nerves in case 1 .

The most interesting data were obtained from study of the SCV and MxCV. Low amplitude of nerve action potentials was the most striking feature. Conduction velocity of the sural nerve was slow in cases 1,2 , and 3 ; it was not estimated in case 4 . Amplitude of the SEP in the sural nerve was severely reduced in two patients. SCV (digit 1-wrist) was normal in two cases, in the low normal range in one, and also slow in one (case 4). SCV (digit 2-wrist) was normal in three cases, and SEP was not evoked in case 4. The amplitude of the SEP (finger-to-wrist segment) was severely reduced in three patients
Table 1 Main features in four cases of ataxia-telangiectasia

\begin{tabular}{|c|c|c|c|c|}
\hline Case & $l$ & 2 & 3 & 4 \\
\hline Age (yr) & 8 & 7 & 12 & 18 \\
\hline Family history & - & - & + & + \\
\hline $\begin{array}{l}\text { Consanguinity of parents } \\
\text { Age of onset of neurological }\end{array}$ & - & + & + & + \\
\hline features (mo) & 16 & 12 & 12 & 8 \\
\hline $\begin{array}{l}\text { Progressive cerebellar ataxia } \\
\text { Diminished or absent }\end{array}$ & + & + & + & + \\
\hline deep reflexes & - & - & + & $t$ \\
\hline Babinski sign & - & - & - & - \\
\hline Romberg's sign & - & - & - & $\begin{array}{l}\text { Not explored. } \\
\text { Confined to } \\
\text { wheel chair }\end{array}$ \\
\hline \multicolumn{5}{|l|}{ Loss of deep and/or } \\
\hline $\begin{array}{l}\text { superficial sensation } \\
\text { Muscular atrophy }\end{array}$ & $\overline{ \pm}$ & $\begin{array}{l}- \\
-\end{array}$ & - & $\begin{array}{l}+ \\
+\end{array}$ \\
\hline Choreoathetosis & $\overrightarrow{+}$ & + & + & + \\
\hline Characteristic facies & + & + & + & + \\
\hline Apraxia of eye movements & + & + & + & + \\
\hline Fixation nystagmus & + & + & + & + \\
\hline Dysarthria & + & + & + & + \\
\hline Mental deficiency & - & - & - & - \\
\hline $\begin{array}{l}\text { Oculocutaneous telangiectasia } \\
\text { Frequent sinopulmonary }\end{array}$ & + & + & + & + \\
\hline infection & + & + & + & + \\
\hline Kyphoscoliosis & - & - & - & + \\
\hline Pes cavus & - & - & - & - \\
\hline Cardiopathy & - & - & - & - \\
\hline Delayed hypersensitivity & & & & \\
\hline responses & + & + & + & + \\
\hline Low or absent serum Ig $A$ & + & - & + & + \\
\hline
\end{tabular}

+ Present.

- Absent.

\pm Doubtful.

and was in the low-normal range in one (Table 2). MxCV (wrist-to-elbow) was performed only in cases 3 and 4 ; in both patients it was slow, and the amplitude of the mixed nerve evoked potentials was reduced considerably (Table 2). Patient 2 had been investigated two years before when results of electrophysiological study were normal.

The $\mathrm{H}$ reflex was checked and found to be absent in cases 1 and 3.

A biopsy study of the sural nerve in patient 1 showed, essentially, loss of the largest myelinated fibres, and demyelination of some fibres (Fig. 2). The ratio between maximum conduction velocity and diameter of the largest fibres was 3.6 (Fig. 2). Muscle biopsy of the same patient was normal.

\section{Discussion}

The most striking feature in our cases of ataxiatelangiectasia is the reduced amplitude of the evoked nerve potentials in upper and lower limbs. Only in the youngest patient (case 2: 7 years of age) was the amplitude of the SEP in the low normal range. However the SCV was normal or, in the oldest patients, moderately reduced. Only slight changes were observed in MCV. Neurogenic patterns were 


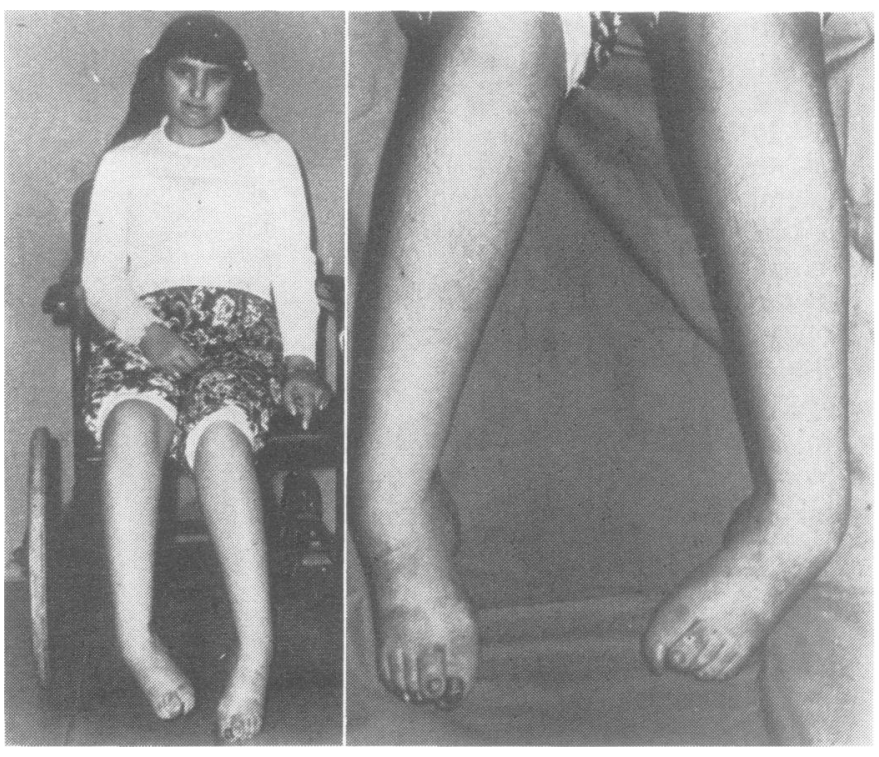

Fig. 1 Case 4, 18 years of age, confined to a wheel chair. Muscular atrophy and equinovarus.

Table 2 Sensory and mixed nerve conduction velocities in four cases of ataxia-telangiectasia

\begin{tabular}{|c|c|c|c|c|c|c|}
\hline & \multicolumn{6}{|c|}{ Electrophysiological measurements } \\
\hline & $\begin{array}{l}\text { Case } 1(8 y r) \\
\text { male }\end{array}$ & $\begin{array}{l}\text { Case } 2(7 y r) \\
\text { male }\end{array}$ & $\begin{array}{l}\text { Case } 3(12 y r) \\
\text { male }\end{array}$ & $\begin{array}{l}\text { Normal mean } \\
(6-12 y r) \pm S D\end{array}$ & $\begin{array}{l}\text { Case } 4(18 y r) \\
\text { female }\end{array}$ & $\begin{array}{l}\text { Normal mean } \\
(17-29 \text { yr }) \pm S D\end{array}$ \\
\hline \multicolumn{7}{|l|}{ Median nerve (sensory) } \\
\hline SCV & 39.6 & 44.6 & 34.7 & $42.4+4.43$ & 36.0 & $44.2+3.28$ \\
\hline Amplitude SEP & 9.0 & 24.0 & 5.0 & $33.6 \pm 4.92$ & 1.0 & $40.3+9.37$ \\
\hline Duration SEP & 1.3 & 1.2 & 1.3 & $1.06 \pm 0.11$ & 1.5 & $0.94 \pm 0.10$ \\
\hline \multicolumn{7}{|l|}{ Digit 2-wrist } \\
\hline SCV & 47.7 & 47.5 & 42.6 & $48.6 \pm 4.72$ & No & $54.6 \pm 4.10$ \\
\hline Amplitude SEP & 5.0 & 11.0 & 2.0 & $15.6 \pm 3.25$ & potential & $16.3 \pm 4.47$ \\
\hline Duration SEP & 1.2 & 1.2 & 1.3 & $1.18 \pm 0.16$ & present & $1.06 \pm 0.07$ \\
\hline \multicolumn{7}{|l|}{ Median nerve (mixed) } \\
\hline \multicolumn{7}{|l|}{ Wrist-elbow } \\
\hline $\mathrm{MxCV}$ & & & 53.7 & $64.7 \pm 5.30$ & 50.9 & $71.0 \pm 3.35$ \\
\hline Amplitude MxEP & & & 5.0 & $41.4 \pm 15.60$ & 0.8 & $33.1 \pm 12.39$ \\
\hline \multicolumn{7}{|l|}{ Sural nerve } \\
\hline SCV & 39.4 & 46.6 & 36.6 & $54.1 \pm 3.47$ & & \\
\hline Amplitude SEP & 2.5 & 5.0 & 2.0 & $12.4 \pm 4.25$ & & \\
\hline
\end{tabular}

Conduction velocity is expressed in metres per second, amplitude (peak to peak) in microvolts, and duration of the nerve evoked potentials in milliseconds. Case 2 was explored two years before with normal findings.

$\mathrm{MxCV}=$ Mixed nerve conduction velocity $(\mathrm{m} / \mathrm{s})$.

MxEP $=$ Evoked action potential of mixed nerve $(\mu \mathrm{V})$.

$\mathrm{SCV}=$ Sensory nerve conduction velocity $(\mathrm{m} / \mathrm{s})$.

$\mathrm{SEP}=$ Evoked action potential of sensory nerve $(\mu \mathrm{V})$.

only seen in the EMG of the oldest patient (case $4: 18$ years of age). These results indicate loss of the large myelinated sensory nerve fibres in all the cases and spinal atrophy in one case.

We think that the electrophysiological abnormalities in our cases of ataxia-telangiectasia are essentially like those described in the apparently 'pure' cases of Friedreich's ataxia. In Friedreich's ataxia the sensory and mixed evoked potentials are very reduced in amplitude or absent, with normal or moderately reduced $\mathrm{SCV}$, whereas the $\mathrm{MCV}$ is normal or slightly slow, and neurogenic EMG patterns are detected only in some of the oldest cases (Preswick, 1968; Downie, 1969; McLeod, 1971; Joong and Halsey, 1973).

The electrophysiological abnormalities detected in ataxia-telangiectasia were less severe than those observed in our cases of Friedreich's ataxia (Cruz Martínez, 1974). In ataxia-telangiectasia, the changes 

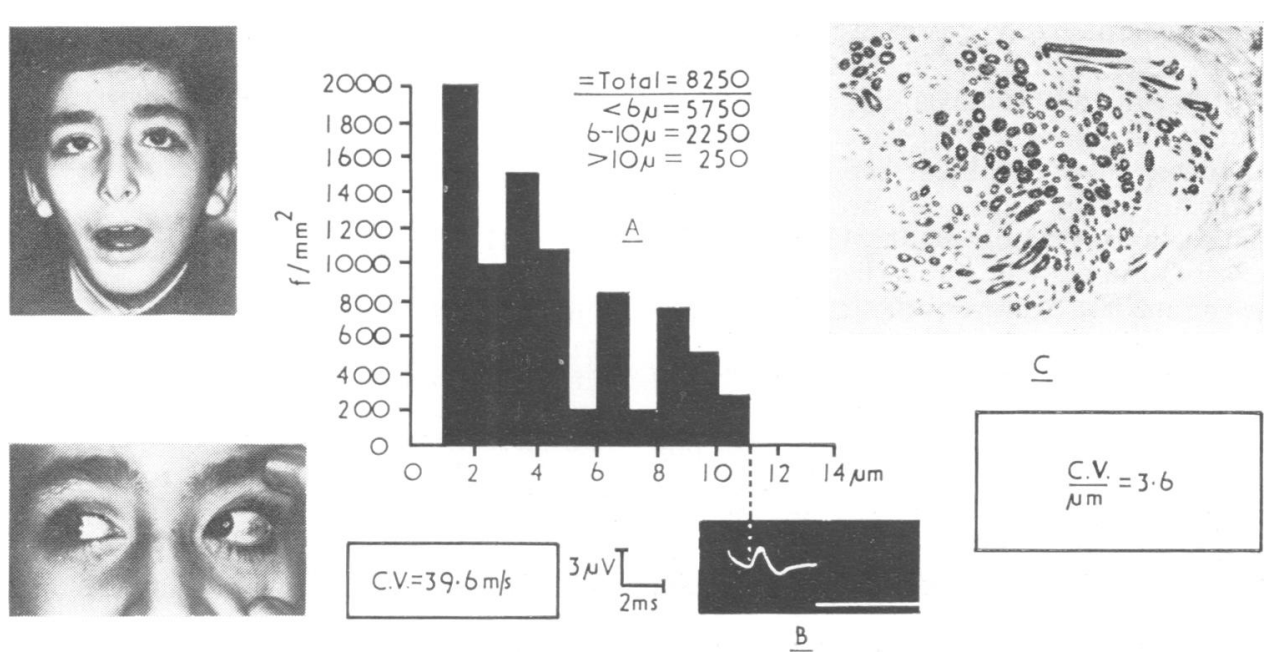

Fig. 2 Case 1, 8 years of age. Ratio between electrophysiological and histopathological findings. Sural nerve. $A$ : distribution of dicmeter and number of myelinated fibres. B: sural nerve action potential recorded at the lower third of the leg, posteriorly. The nerve was stimulated at the lateral malleolus. $C$ : focal loss of largest myelinated fibres. The normal ratio between conduction velocity and the diameter of the largest fibres $(4.4 \pm 0.37)$ has been published by Behse et al. (1975).

were more severe in older than in younger patients, and were detected without clinical evidence of peripheral neuropathy in cases 1,2 , and 3 .

Since the electrophysiological abnormalities are similar, a comparison of the pathology in peripheral nerves between both diseases could be interesting. The information in the literature about the pathology of the peripheral nerve in Friedreich's ataxia is welldocumented. Sural nerve biopsy shows a selective decrease in large myelinated fibres (Dyck et al., 1968), and the compound action potentials in sural nerve removed at biopsy show a selective reduction in amplitude of the alpha potential (Lambert and Dyck, 1968), with normal or moderately reduced conduction velocity. These results are consistent with degeneration of the large neurones of the dorsal root ganglia. Dyck and Lais (1973) later found segmental demyelination and remyelination in cutaneous nerves in Friedreich's ataxia, probably secondary to axonal atrophy. These findings would explain the electrophysiological abnormalities.

Unfortunately, information about the pathology of the peripheral nerve in ataxia-telangiectasia is not extensive. Loss of myelinated nerve fibres in the posterior columns of the spinal cord, degenerative changes in the anterior horns, and neuromelanosis, reduction of the number of satellite cells and nerve cells smaller than normal in spinal root ganglia, have been described in necropsy studies by Boder and Sedgwick (1958), Strich (1966) and Aguilar et al. (1968). In biopsy studies of sural nerve, small changes are described: absence of demyelination, few enlarged hyperchromatic Schwann cell nuclei, and presence of lipid cytosomes in Schwann cells (Gardner and Goodman, 1969; Goodman et al., 1959). Muscle biopsy is described usually as normal or, in older patients, with findings suggestive of a denervation atrophy (Engel et al., 1966; Gardner and Goodman, 1969).

In the sural nerve biopsy of our case 1 , a reduced number of large myelinated fibres and demyelination of some fibres were found. These results would account for the reduction in amplitude of the nerve evoked potentials and the absence of the $\mathrm{H}$ reflex which we observed. The ratio between maximum conduction velocity and diameter of the largest fibres was 3.6 (Fig. 2); this value is in the lower part of the normal range $(4.4 \pm 0.37)$ published by Behse et al. (1975). Normal (or within low limits) ratios between maximum conduction velocity and diameter of the largest fibres have been observed in axonal degeneration (Behse et al., 1975). Other electrophysiological abnormalities, such as normal or slight changes in conduction velocity, have been published previously (Dunn et al., 1964; Goodman et al., 1969), and are similar to our findings. Fasciculation, fibrillation, and reduction in the number of motor units found in case 4 have also been published in long-surviving patients (Goodman et al., 1969).

Although the electrophysiological findings are similar, some clinical and biological features are different between ataxia-telangiectasia and Fried- 
reich's ataxia. Cardiopathy, pes cavus, loss of deep sensation, Romberg and Babinski signs are habitual or frequent in Friedreich's ataxia, but not in ataxiatelangiectasia. Impairment of delayed hypersensitivity responses, low or absent serum $\operatorname{IgA}$, and oculocutaneous telangiectasias are not described in Friedreich's ataxia (Young et al., 1964). Ataxiatelangiectasia usually has an earlier onset than Friedreich's ataxia. However, the clinical manifestations of ataxia-telangiectasia are not definitively established, and new neurological, skin, and hair features can be observed in long-surviving patients. In the oldest patients, spinal muscular atrophy (Goodman et al., 1969), features of peripheral neuropathy (Engel et al., 1966; Gardner and Goodman, 1969), and progressive evolution to resemble Friedreich's ataxia are described (Martin, 1966).

The progression of the electrophysiological abnormalities is clear in our patients. Case 2 was explored at the age of 5 years with normal electrophysiological findings. Later, at age 7 years, the amplitude of the SEP was in the low limits of the normal range. In patients 1 and 3 (8 and 12 years of age), the electrophysiological abnormalities were more severe than in case 2 . The oldest patient (case 4) had absent deep reflexes, loss of deep sensation, muscular atrophy, and deformities in lower limbs. Electrophysiologically, neurogenic atrophy, slight slowing of motor and sensory conduction velocities, and severe reduction in amplitude of evoked nerve "potentials were found in this case.

Our conclusion is that reduction in amplitude of the nerve evoked potentials is the earliest and most striking electrophysiological feature in ataxia telangiectasia. This abnormality can be observed without clinical evidence of peripheral neuropathy. Later, in the older patients, mild reduction of the MCV and SCV, and suggestive findings of spinal atrophy can be found.

We wish to thank Dr D. Urra and Dr E. Varela for the clinical study, and Dr S. Ramón y Cajal and Dr A. Martínez for the neuropathological report.

\section{References}

Aguilar, M. J., Kamoshita, S., Landing, B. H., Boder, E. and Sedgwick, R. P. (1968). Pathological observations in ataxia-telangiectasia. A report on 5 cases. Journal of Neuropathology and Experimental Neurology, 27, 659-676.

Behse, F., Buchthal, F., and Rosenfalck, A. (1975). Sensory conduction and quantitation of biopsy findings in the sural nerve. In Studies on Neuromuscular Diseases, pp. 229-231. Edited by K. Kunze and J. E. Desmedt. Karger: Basel.
Boder, E., and Sedgwick, R. P. (1957). A familial syndrome of progressive cerebellar ataxia, oculocutaneous telangiectasia and frequent pulmonary infection. A preliminary report on 7 children, an autopsy and a case history. University of South California Medical Bulletin, 9, 15-28.

Boder, E., and Sedgwick, R. P. (1958). Ataxia-telangiectasia. A familial syndrome of progressive cerebellar ataxia, oculocutaneous telangiectasia and frequent pulmonary infection. Pediatrics, 21, 526-554.

Cruz Martínez, A. (1974). Alteraciones de la conducción nerviosa en la ataxia de Friedreich. Comparación con los resultados obtenidos en otras ataxias y enfermedades heredofamiliares. Revista Clinica Española, 134, 249-258.

Downie, A. W. (1969). Studies in nerve conduction. In Disorders of Voluntary Muscle, pp. 785-812. Edited by J. N. Walton. Churchill: London.

Dunn, H. G., Meuwissen, H., Livingstone, C. S., and Pump, K. K. (1964). Ataxia-telangiectasia. Canadian Medical Association Journal, 91, 1106-1118.

Dyck, P. J., Gutrecht, J. A., and Bastron, J. A. (1968). Histologic and teased-fiber measurements of sural nerve in disorders of lower motor and primary sensory neurons. Mayo Clinic Proceedings, 48, 81-123.

Dyck, P. J., and Lais, C. (1973). Evidence for segmental demyelination secondary to axonal degeneration in Friedreich's ataxia. In Clinical Studies in Myology pt. 2, pp. 253-263. Edited by B. A. Kakulas. Excerpt负 Medica: Amsterdam.

Engel, W. K., McFarlin, D. E., Drews, G., and Wochner물 R. D. (1966). Protein abnormalities in neuromuscular diseases. Journal of American Medical Association 195, 754-760.

Fireman, P., Boesman, M., and Gitlin, D. (1964). dysgammaglobulinaemia with deficient gamma $1 \mathrm{~A}$ (B2A)-globulin. Lancet, 1, 1193-1195.

Gardner, M. B., and Goodman, W. N. (1969). Ataxiatelangiectasia. Electron microscopy study of a nerve biopsy. Bulletin of the Los Angeles Neurological Society, 34, 23-38.

Goodman, W. N., Cooper, W. C., Kessler, G. B., Fischer, M. S., and Gardner, M. B. (1969). Ataxia-telangiectasia. A report of 2 cases in siblings presenting a picture of progressive spinal muscular atrophy. Bulletin of the Los Angeles Neurological Society, 34, 1-22.

Joong, S. H., and Halsey, J. H. (1973). Abnormality in nerve potentials in Friedreich's ataxia. Neurology (Minneap.), 23, 52-54.

Karpati, G., Eisen, A. H., Andermann, F., Bacal, H. L., and Robb, J. P. (1965). Ataxia-telangiectasia. Further observations and report of 8 cases. American Journal of Diseases of Children, 110, 51-63.

Lambert, E. H., and Dyck, P. J. (1968). Compound action potentials of human sural nerve biopsies. Electroencephalography and Clinical Neurophysiology, 25, 399-400.

Louis-Bar, D. (1941). Sur un syndrome progressif comprenant des télangiectasies capillaires, cutanées et conjonctivales symétriques, à disposition naevoïde et de troubles cérébelleux. Confinia Neurologia (Basel), 4, 802-819. 
McLeod, J. G. (1971). An electrophysiological and pathological study of peripheral nerves in Friedreich's ataxia. Journal of the Neurological Sciences, 12, 333-349.

Martin, L. (1966). The nosological position of ataxiatelangiectasia. Retrospective study of the first observation. Journal of the Neurological Sciences, 3, 2-9.

Peterson, R. D. A., Blaw, M., and Good, R. A. (1963). Ataxia-telangiectasia: a possible clinical counterpart of the animals rendered immunologically incompetent by thymectomy. Journal of Pediatrics, 63, 701-703.

Preswick, G. (1968). The peripheral neuropathy of Friedreich's ataxia. Electroencephalography and Clinical Neurophysiology, 35, 399.
Strich, S. (1966). Pathological findings in three cases of ataxia-telangiectasia. Journal of Neurology, Neurosurgery, and Psychiatry, 29, 489-499.

Syllabc, L., and Henner, K. (1926). Contribution à l'indépendance de l'athétose double idiopathique et congénitale. Revue Neurologique, 1, 541-562.

Tadjoedin, M. K., and Fraser, F. C. (1965). Heredity of ataxia-telangiectasia (Louis-Bar syndrome). American Journal of Diseases in Childhood, 110, 64-68.

Young, R. R., Austen, K. F., and Moser, H. W. (1964). Abnormalities of serum gamma IA globulin and ataxiatelangiectasia. Medicine (Balt.), 43, 423-433. 